\title{
Electrocardiogram abnormalities in residents in cold homes: a cross-sectional analysis of the nationwide Smart Wellness Housing survey in Japan
}

Wataru Umishio ${ }^{1,2^{*}} \mathbb{0}$, Toshiharu Ikaga ${ }^{2}$, Kazuomi Kario ${ }^{3}$, Yoshihisa Fujino ${ }^{4}$, Masaru Suzuki ${ }^{5}$, Shintaro Ando ${ }^{6}$, Tanji Hoshi ${ }^{7}$, Takesumi Yoshimura ${ }^{8}$, Hiroshi Yoshino ${ }^{9}$ and Shuzo Murakami ${ }^{10}$ on behalf of the SWH Survey Group

\begin{abstract}
Background: Excess winter mortality caused by cardiovascular disease is particularly profound in cold houses. Consistent with this, accumulating evidence indicates that low indoor temperatures at home increase blood pressure. However, it remains unclear whether low indoor temperatures affect other cardiovascular biomarkers. In its latest list of priority medical devices for management of cardiovascular diseases, the World Health Organization (WHO) included electrocardiography systems as capital medical devices. We therefore examined the association between indoor temperature and electrocardiogram findings.

Methods: We collected electrocardiogram data from 1480 participants during health checkups. We also measured the indoor temperature in the living room and bedroom for 2 weeks in winter, and divided participants into those living in warm houses (average exposure temperature $\geq 18^{\circ} \mathrm{C}$ ), slightly cold houses $\left(12-18{ }^{\circ} \mathrm{C}\right)$, and cold houses $(<12$ ${ }^{\circ} \mathrm{C}$ ) in accordance with guidelines issued by the WHO and United Kingdom. The association between indoor temperature (warm vs. slightly cold vs. cold houses) and electrocardiogram findings was analyzed using multivariate logistic regression models, with adjustment for confounders such as demographics (e.g., age, sex, body mass index, household income), lifestyle (e.g., eating habit, exercise, smoking, alcohol drinking), and region.
\end{abstract}

Results: The average temperature at home was $14.7^{\circ} \mathrm{C}$, and 238,924 , and 318 participants lived in warm, slightly cold, and cold houses, respectively. Electrocardiogram abnormalities were observed in 17.6\%, 25.4\%, and 30.2\% of participants living in warm, slightly cold, and cold houses, respectively ( $p=0.003$, chi-squared test). Compared to participants living in warm houses, the odds ratio of having electrocardiogram abnormalities was 1.79 (95\% confidence interval: $1.14-2.81, p=0.011)$ for those living in slightly cold houses and 2.18 (95\% confidence interval: $1.27-3.75, p=$ 0.005) for those living in cold houses.

Conclusions: In addition to blood pressure, living in cold houses may have adverse effects on electrocardiogram. Conversely, keeping the indoor thermal environment within an appropriate range through a combination of living

\footnotetext{
*Correspondence: umishio.w.aa@m.titech.ac.jp

${ }^{1}$ Department of Architecture and Building Engineering, School

of Environment and Society, Tokyo Institute of Technology, W8-11, 2-12-1,

Ookayama, Meguro-ku, Tokyo 152-8552, Japan

Full list of author information is available at the end of the article
}

(c) The Author(s) 2021. Open Access This article is licensed under a Creative Commons Attribution 4.0 International License, which permits use, sharing, adaptation, distribution and reproduction in any medium or format, as long as you give appropriate credit to the original author(s) and the source, provide a link to the Creative Commons licence, and indicate if changes were made. The images or other third party material in this article are included in the article's Creative Commons licence, unless indicated otherwise in a credit line to the material. If material is not included in the article's Creative Commons licence and your intended use is not permitted by statutory regulation or exceeds the permitted use, you will need to obtain permission directly from the copyright holder. To view a copy of this licence, visit http://creativecommons.org/licenses/by/4.0/. The Creative Commons Public Domain Dedication waiver (http://creativeco mmons.org/publicdomain/zero/1.0/) applies to the data made available in this article, unless otherwise stated in a credit line to the data. 
in highly thermal insulated houses and appropriate use of heating devices may contribute to good cardiovascular health.

Trial registration: The trial was retrospectively registered on 27 Dec 2017 to the University hospital Medical Information Network Clinical Trials Registry (UMIN-CTR, https://www.umin.ac.jp/ctr/, registration identifier number UMINO 00030601).

Keywords: Electrocardiogram, Cardiovascular disease, Indoor temperature, Housing, Winter

\section{Background}

The World Health Organization (WHO) has issued several guidelines on the prevention of cardiovascular disease (CVD), the world's leading cause of death [1-5]. These guidelines highlight four important risk factors for CVD: (1) unhealthy diet, (2) physical inactivity, (3) tobacco use, and (4) harmful use of alcohol. To put the guidelines into action, in 2016, WHO and the United States Centers for Disease Control and Prevention (US CDC) launched the Global Hearts Initiative to promote better lifestyle habits, such as reducing salt intake through SHAKE packages [6], increasing physical activity through ACTIVE packages [7], and improving smoking habit through MPOWER packages [8]. However, the ability to improve lifestyle habits is limited because it depends on the efforts of the individual. Meanwhile, improving one's living environment is attracting attention as an additional approach for preventing CVD.

In the relationship between living environment and CVD, excess winter mortality (EWM), a phenomenon in which the mortality rate rises sharply in winter [912], is an inevitable issue. According to estimations by the WHO Regional Office for Europe, 50-70\% of EWM is attributed to CVD [13], and EWM caused by CVD is particularly profound in cold houses [14]. The WHO's 2018 Housing and health guidelines [15] list "low indoor temperatures and insulation" as one of five priority issues. The guidelines indicate that the mechanism of cardiovascular (CV) events is partially explained by a rise in blood pressure (BP) due to cold exposure. Consistent with this, studies finding a relationship between indoor temperature and BP are accumulating [16-18]. However, it remains unclear whether low indoor temperatures affect other $\mathrm{CV}$ biomarkers.

Electrocardiogram (ECG), a test that measures the heart's electrical activity, is one of the most common methods used to assess $\mathrm{CV}$ health. In their latest list of priority medical devices for management of CVD, the WHO included ECG as a capital medical device for early detection of CVD [19]. Additionally, previous studies have reported close associations between ECG findings and CVD risk $[20,21]$. Thus, it would be valuable to verify whether low indoor temperatures are associated with ECG abnormalities. However, the association has not been well investigated.

We conducted a nationwide epidemiological survey on housing and health in Japan, named the Smart Wellness Housing (SWH) survey. In Japan, an estimated 39\% of existing houses are uninsulated [22], and a large proportion of residents live in houses with low indoor temperatures [23]. There is a concern that living in such houses may have adverse effects on health. The aim of this paper was to determine the association between the indoor temperature at home and ECG findings.

\section{Methods}

\section{Ethical issues}

The study was conducted according to the principles of the Declaration of Helsinki. The study protocol and informed consent procedure were approved by the Hattori Clinic Ethics Review Board (Approval No. S1410-J03). This review board consists of experts in medicine, bioethics, and law and is certified by the Ministry of Health, Labour, and Welfare (Accreditation No. CRB3180027). The study protocol was registered at the University hospital Medical Information Network Clinical Trials Registry (UMIN000030601). All participants provided written informed consent to participate and to have their data published as a group.

\section{Study design}

The aims and study design of the SWH survey are reported elsewhere [18]. Briefly, the survey was conducted as a non-randomized controlled trial with an insulation retrofitting group and non-insulation retrofitting (control) group to examine the health benefits of insulation retrofitting houses. Participants were recruited by construction companies throughout all 47 prefectures in 8 regions in Japan (Figure S1). Inclusion criteria were (1) intention to conduct insulation retrofitting, (2) age over 20 years, and (3) pre-renovation house that did not meet S (Supreme) standards of the "Act on the Promotion of Dissemination of Long-Lasting Quality Housing" in Japan. In this paper, we performed a cross-sectional analysis of data obtained in the baseline (before insulation 
retrofitting) survey of FY 2014 to 2017. We focused on data obtained before insulation retrofitting to reflect the actual condition of houses in Japan, most of which have low insulation performance [22].

\section{Electrocardiogram measurements}

Participants were asked to submit the results of a health checkup which was conducted within a year of the survey period. In Japan, health checkups conducted by doctors are required once a year in accordance with the Industrial Safety and Health Act. Items included in the health checkup are (1) past medical history; (2) subjective and objective symptoms; (3) height, weight, abdominal girth, and visual and hearing acuity; (4) chest X-ray; (5) BP; (6) anemia; (7) liver function; (8) blood lipids; (9) blood glucose; (10) urine; and (11) ECG. We examined ECG data in the present study. The 12-lead ECG test requires that participants lay on their back on a bed while a medical technologist places electrodes on their chest, wrists, and ankles to obtain ECG waveforms over a period of a few minutes. Doctors judged whether or not participants had abnormal ECG waveforms. Examples of abnormalities in ECG are shown in Table S1.

\section{Indoor temperature measurements}

Indoor temperature and relative humidity at $1.0 \mathrm{~m}$ above the floor were measured in participants' living room and bedroom at 10-min intervals (TR-72wf; T\&D Corp., Nagano, Japan) in winter (November-March). When installing the temperature and humidity loggers, the device was placed (1) out of direct sunlight and (2) far away from heating equipment or heat-generating devices like refrigerators and televisions to avoid extreme outlier measurements. Outdoor temperature was obtained from the closest local meteorological observatory to each participant's house.

\section{Other measurements}

Participants were also asked to complete a questionnaire survey that inquired about demographics such as age, sex, height, weight, and household income; lifestyle indicators such as eating habit, exercise, smoking, and alcohol consumption; and health conditions related to CVD. Participants indicated their household income by choosing from multiple choices, which were later reclassified as low $(<2$ million JPY), middle $(2-6$ million JPY), and high ( $\geq 6$ million JPY) in accordance with the National Health and Nutrition Survey. The salt check sheet score and frequency of vegetable intake were used as measures of eating habit, with the former classified in 4 groups (low (0-8 points), medium (9-13 points), high (14-19 points), or very high ( $\geq 20$ points)) [24] and the latter classified according to whether or not participants ate vegetables regularly. Exercise, smoking, and alcohol drinking were evaluated as twovalued variables; that is, whether or not participants did regular moderate exercise, whether or not they were a current smoker, and whether or not they were a current drinker, respectively. Regarding health conditions, participants were asked whether they visited the hospital for a list of diseases. A diary survey was also conducted, in which participants provided details of their waking time, bedtime, and time spent at home on a daily basis.

\section{Statistical analysis}

First, we defined warm, slightly cold, and cold houses. We calculated participants' exposure temperature by extracting the living room temperature when participants were at home (excluding the period while they were asleep) and the bedroom temperature while they were asleep based on information from the diary survey. Details of the definition of participants' exposure temperature are shown in Figure S2. Subsequently, we divided participants into three groups according to the average exposure temperature at home: $\geq 18{ }^{\circ} \mathrm{C}$ (warm houses), $12-18{ }^{\circ} \mathrm{C}$ (slightly cold houses), and $<12{ }^{\circ} \mathrm{C}$ (cold houses). These thresholds were chosen in accordance with the WHO Housing and health guidelines for "a safe and well-balanced indoor temperature" during cold seasons $\left(18{ }^{\circ} \mathrm{C}\right)$ [15] and a UK report on the temperature at which CVD risk begins to increase $\left(12{ }^{\circ} \mathrm{C}\right)$ [25].

Inter-group comparisons of proportion values were performed using the chi-squared test. The association between exposure temperature at home and ECG findings was evaluated using univariate and multivariate logistic regression analyses. Whether or not participants' ECG findings were abnormal was inputted as the objective variable, and the exposure temperature (warm vs. slightly cold vs cold houses) was inputted as the explanatory variable. The analyses were adjusted for participants' basic characteristics such as age ( $\geq 65$ or $<65$ years), sex, body mass index (BMI $=$ weight $[\mathrm{kg}] /$ height $[\mathrm{m}]^{2} ; \geq 25$ or $<25 \mathrm{~kg} / \mathrm{m}^{2}$ ), household income (low, middle, or high), salt check sheet score (low, medium, high, or very high), vegetable intake (regularly or not), exercise habit (regularly or not), smoking status (currently or not), alcohol drinking status (currently or not), antihypertensive drug use (currently or not), outdoor temperature in winter (as a continuous variable), and region in Japan (8 regions in Figure S1 as a dummy variable). Additionally, the season during which the health checkup was performed (whether or not it was 
in winter) was inputted into the model to account for seasonal variations. All $P$ values were two sided, and a two-sided $P$ value less than 0.05 was considered statistically significant. All analyses were performed using SPSS Ver. 26 (SPSS Inc., Chicago, Illinois, USA).

\section{Results}

\section{Definition of warm, slightly cold, and cold houses based} on indoor temperature

Figure 1 shows the selection of valid samples. Of 3775 participants in the SWH survey, 2230 submitted health checkup data and 2156 had valid data. Valid samples had different health checkup items because the items can be omitted at the doctors' discretion. A total of 1480 participants had ECG data.

The distribution of exposure temperature is shown in Fig. 2. (The distribution of average exposure time to living room and bedroom temperature is also shown in Figure S3.) The average exposure temperature was $14.7{ }^{\circ} \mathrm{C}$. Based on the results of Fig. 2, we divided the participants into those living in warm $\left(\geq 18{ }^{\circ} \mathrm{C}\right)$, slightly cold (12-18 $\left.{ }^{\circ} \mathrm{C}\right)$, and cold $\left(<12{ }^{\circ} \mathrm{C}\right)$ houses. The sample size of the three groups was 238, 924, and 318, respectively. Figure 3 shows the changes in indoor and outdoor temperature

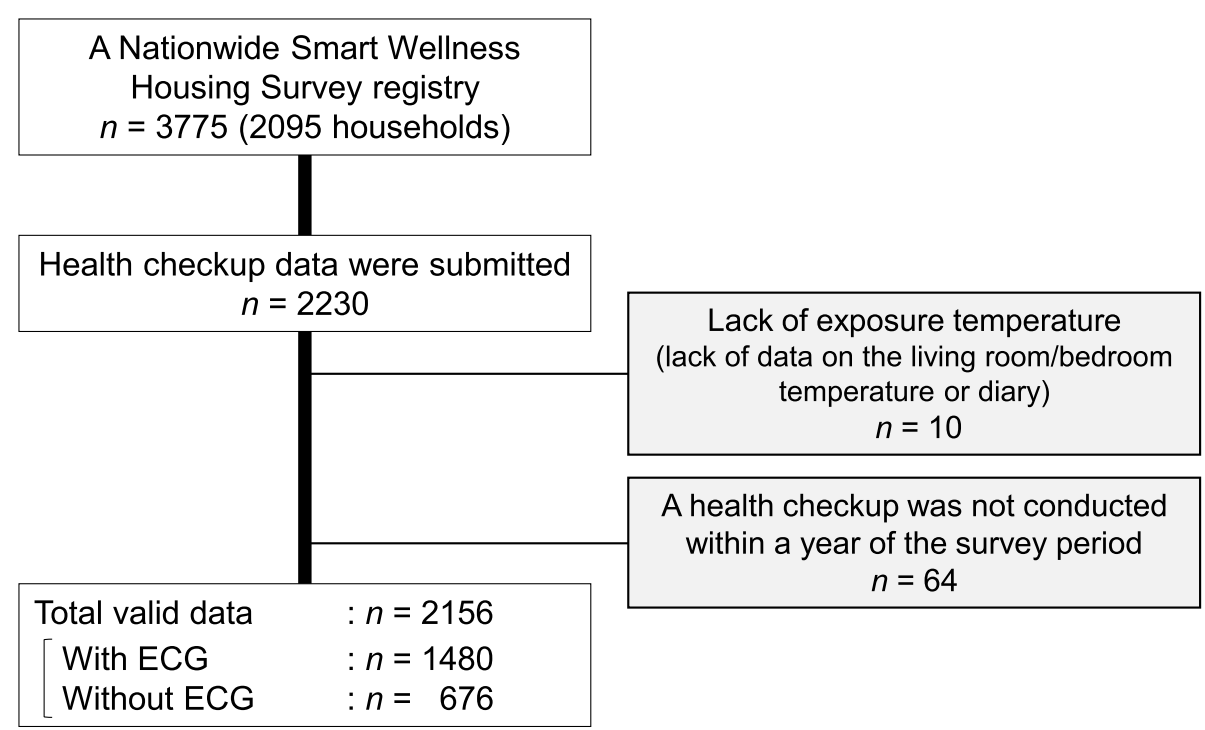

Fig. 1 Flow of the selection of valid samples. ECG electrocardiogram

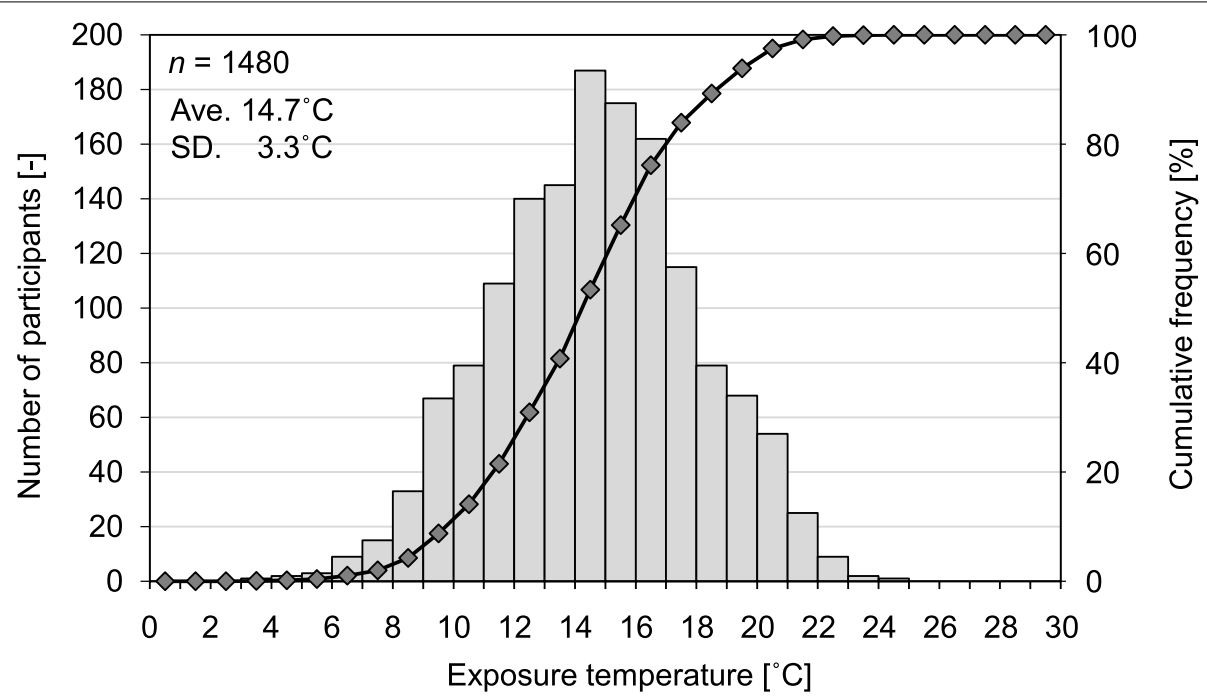

Fig. 2 Distribution of average exposure temperature 

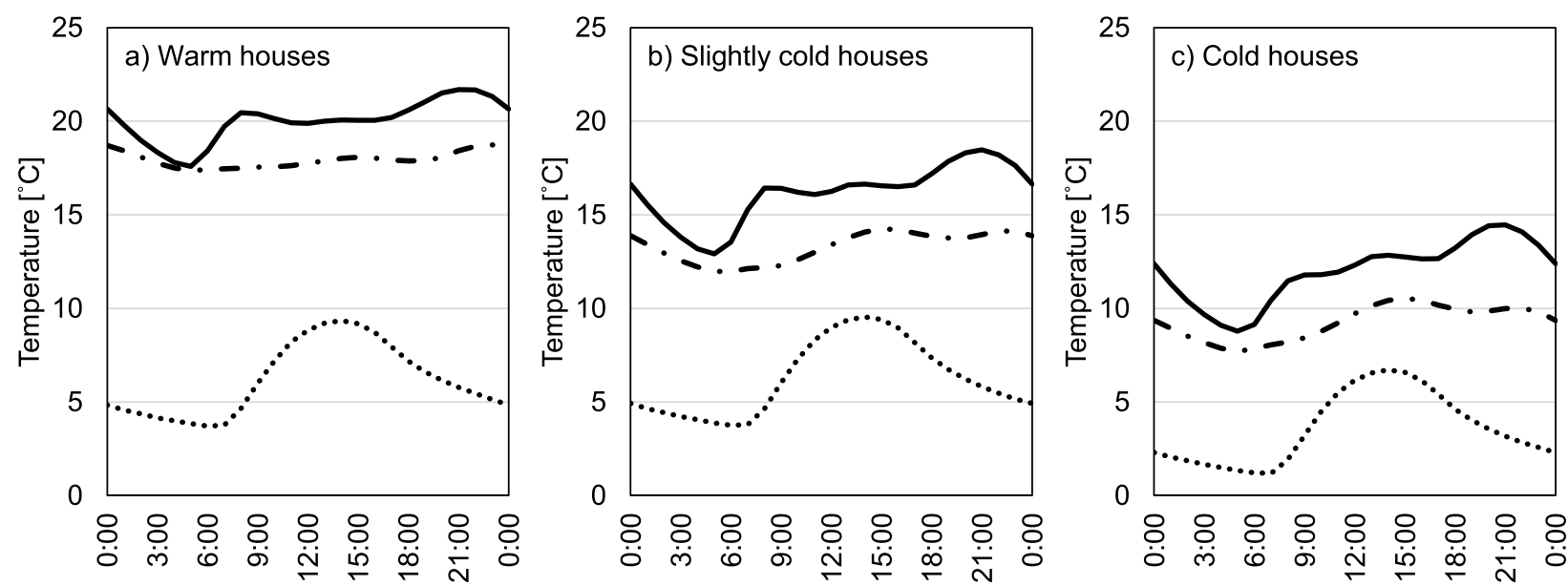

Fig. 3 Fluctuation of indoor and outdoor temperature throughout a day in the three groups. Solid line shows the living room temperature, dash-dot-dash line shows the bedroom temperature, and dotted line shows the outdoor temperature

throughout a day in the three groups. The average living room/bedroom temperature was $20.0 / 18.0{ }^{\circ} \mathrm{C}$ for warm houses, $16.2 / 13.3^{\circ} \mathrm{C}$ for slightly cold houses, and $12.0 / 9.3$ ${ }^{\circ} \mathrm{C}$ for cold houses. Although the outdoor temperature of warm houses was almost the same as that of slightly cold houses, the average living room/bedroom temperature differed by $3.9 / 4.7^{\circ} \mathrm{C}$. Focusing on intra-day variations, all three groups showed the same trend in which the living room and bedroom temperature dropped to the minimum value at $5 \mathrm{AM}$. Subsequently, only the living room temperature rose sharply in the morning and gradually increased to the maximum value at $9 \mathrm{PM}$.

\section{Study profile}

Table 1 shows the baseline characteristics of the participants overall and by group. Regarding locations, participants living in the Kanto, Chubu, and Kinki region, which are populated areas in Japan, accounted for $60 \%$. In the Hokkaido region where outdoor temperature is the lowest in Japan, there were many participants living in warm houses. On the other hand, in the Kyushu region which is located in the southwestern area of Japan and considered to have a mild climate, a large number of participants lived in slightly cold or cold houses. The above results suggested the necessity to consider regions in the following analyses.

Regarding individual attributes, about half of the participants were men, the average age was 56 years and about $25 \%$ were 65 years and older. The average BMI was $22.8 \mathrm{~kg} / \mathrm{m} 2$ and approximately $20 \%$ were classified as overweight. Further, $45 \%$ of participants were from high income households, which is a larger proportion than that reported by the National Health and Nutrition Survey in Japan (27.4\%). While the number of patients with stroke, angina/myocardial infarction, and diabetes was small, more than $10 \%$ had hyperlipidemia and hypertension. Participants' basic characteristics were adjusted in the subsequent multivariate logistic regression model to account for differences among the three groups.

The proportion (\%) was calculated excluding missing values

\section{Comparison of electrocardiogram data among warm, slightly cold, and cold houses}

Figure 4 shows the proportion of participants with ECG abnormalities living in warm, slightly cold, and cold houses. The number of participants with ECG abnormalities increased with colder houses. ECG abnormalities were identified in $17.6 \%, 25.4 \%$, and $30.2 \%$ of participants living in warm, slightly cold, and cold houses, respectively ( $p=0.003$, chi-squared test). The results of logistic regression analyses are shown in Table 2. Compared to participants living in warm houses, the adjusted odds ratio of having ECG abnormalities was 1.79 (95\% CI: $1.14-2.81, p=0.011)$ for those living in slightly cold houses and 2.18 (95\%CI: $1.27-3.75, p=0.005$ ) for those living in cold houses.

\section{Discussion}

To our knowledge, this is the first study to assess the association between ECG abnormalities and daily exposure temperature measured in participants' homes across 2 weeks in winter. Although a large number of studies have examined seasonal variations in $\mathrm{CV}$ biomarkers such as blood pressure [26-29], blood lipids [30-32], and blood glucose level $[33,34]$ and the relationship between these biomarkers and outdoor temperature [35-38], few studies have examined the relationship between $\mathrm{CV}$ 
Table 1 Basic characteristics of participants in the baseline survey in winter

\begin{tabular}{|c|c|c|c|c|c|}
\hline Variable & $\begin{array}{l}\text { Overall } \\
N(\%)\end{array}$ & $\begin{array}{l}\text { Warm }\left(\geq 18^{\circ} \mathrm{C}\right) \\
N(\%)\end{array}$ & $\begin{array}{l}\text { Slightly cold }\left(12-18^{\circ} \mathrm{C}\right) \\
N(\%)\end{array}$ & $\begin{array}{l}\text { Cold }\left(<12^{\circ} \mathrm{C}\right) \\
N(\%)\end{array}$ & $\begin{array}{l}p \text { for the } x^{2} \text { test } \\
-\end{array}$ \\
\hline \multicolumn{6}{|l|}{ Location } \\
\hline Region & & & & & $<0.001$ \\
\hline Hokkaido region & $73(5)$ & $37(16)$ & $32(3)$ & $4(1)$ & \\
\hline Tohoku region & $156(11)$ & $15(6)$ & $78(8)$ & $63(20)$ & \\
\hline Kanto region & $280(19)$ & $60(25)$ & $173(19)$ & $47(15)$ & \\
\hline Chubu region & $305(21)$ & $38(16)$ & $200(22)$ & $67(21)$ & \\
\hline Kinki region & $297(20)$ & $48(20)$ & $194(21)$ & $55(17)$ & \\
\hline Chugoku region & $98(7)$ & $14(6)$ & $58(6)$ & $26(8)$ & \\
\hline Shikoku region & $69(5)$ & $14(6)$ & $44(5)$ & $11(3)$ & \\
\hline Kyushu region & $202(14)$ & $12(5)$ & $145(16)$ & $45(14)$ & \\
\hline \multicolumn{6}{|l|}{ Demographics } \\
\hline Age ( $\geq 65$ years) & $352(24)$ & $44(18)$ & $222(24)$ & $86(27)$ & 0.061 \\
\hline Men & 816 & $136(57)$ & $518(56)$ & $162(51)$ & 0.227 \\
\hline $\begin{array}{l}\text { Body mass index }(\geq 25 \\
\left.\mathrm{kg} / \mathrm{m}^{2}\right)\end{array}$ & $318(21)$ & 53 & $197(21)$ & $68(21)$ & 0.950 \\
\hline Household income & & & & & 0.007 \\
\hline Low (<2 million JPY) & $105(8)$ & $12(6)$ & $62(7)$ & $31(10)$ & \\
\hline JPY) Middle (2-6 million & $647(47)$ & $105(48)$ & $384(45)$ & $158(53)$ & \\
\hline High ( $\geq 6$ million JPY) & () 616 (45) & $101(46)$ & $407(48)$ & $108(36)$ & \\
\hline \multicolumn{6}{|c|}{ Lifestyle } \\
\hline Salt check sheet & & & & & 0.617 \\
\hline Low (0-8 points) & $180(13)$ & $28(12)$ & $109(12)$ & $43(14)$ & \\
\hline $\begin{array}{l}\text { Medium (9-13 } \\
\text { points) }\end{array}$ & $566(40)$ & $101(44)$ & $357(41)$ & $108(36)$ & \\
\hline High (14-19 points) & $555(39)$ & $84(36)$ & $349(40)$ & $122(41)$ & \\
\hline $\begin{array}{l}\text { Very high }(\geq 20 \\
\text { points) }\end{array}$ & $112(8)$ & $18(8)$ & $66(7)$ & $28(9)$ & \\
\hline $\begin{array}{l}\text { Regular vegetable } \\
\text { intake }\end{array}$ & $1111(75)$ & $179(75)$ & $687(75)$ & $245(77)$ & 0.716 \\
\hline Regular exercise & $441(30)$ & $66(28)$ & $255(28)$ & $120(38)$ & 0.003 \\
\hline Current smoker & $224(16)$ & $40(18)$ & $138(16)$ & $46(16)$ & 0.803 \\
\hline Current drinker & $872(60)$ & $141(60)$ & $568(62)$ & $163(52)$ & 0.005 \\
\hline $\begin{array}{l}\text { Antihypertensive drug } \\
\text { use }\end{array}$ & $325(23)$ & $35(15)$ & $212(24)$ & $78(25)$ & 0.007 \\
\hline \multicolumn{6}{|l|}{ Health condition } \\
\hline Stroke & $17(1)$ & $4(2)$ & $9(1)$ & $4(1)$ & 0.649 \\
\hline $\begin{array}{l}\text { Angina/Myocardial } \\
\text { infarction }\end{array}$ & $35(2)$ & $5(2)$ & $22(2)$ & $8(3)$ & 0.944 \\
\hline Diabetes & $87(6)$ & $14(6)$ & $59(7)$ & $14(5)$ & 0.452 \\
\hline Hyperlipidemia & $259(18)$ & $31(13)$ & $167(19)$ & $61(20)$ & 0.107 \\
\hline Hypertension & $312(22)$ & $31(13)$ & $207(23)$ & $74(24)$ & 0.003 \\
\hline
\end{tabular}

biomarkers and the indoor temperature at home. Unlike the outdoor temperature, the indoor temperature is a controllable factor. Therefore, evidence on the relationship between $\mathrm{CV}$ biomarkers and indoor temperature can be used to prevent CVD, and in turn reduce EWM.
As mentioned previously, there is accumulating evidence that low indoor temperatures increase BP [16-18]. However, because BP changes from beat to beat, it is unclear whether the effect of low indoor temperatures on CV health is transient. Therefore, it is important to clarify the association between indoor temperature and 


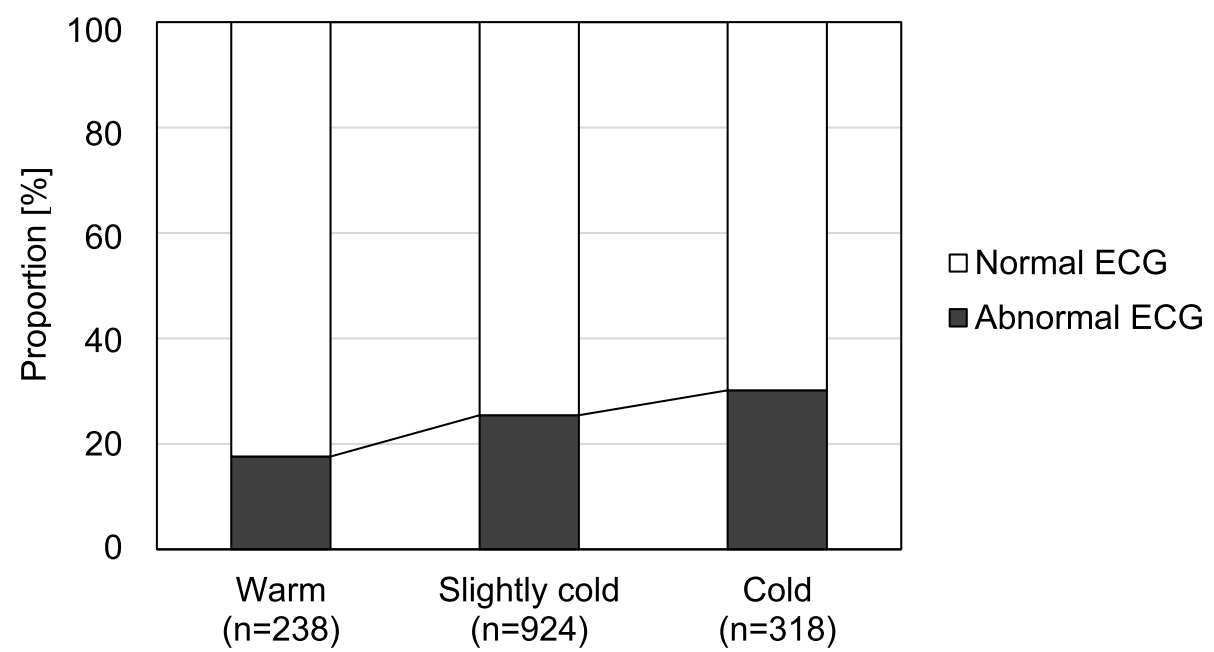

Fig. 4 Proportion of residents with electrocardiogram abnormalities in the three groups. ECG electrocardiogram

Table 2 Associations between electrocardiogram data and indoor temperature (warm vs. slightly cold vs cold houses)

\begin{tabular}{|c|c|c|c|c|c|c|}
\hline \multirow[b]{2}{*}{ Explanatory variable } & \multicolumn{3}{|l|}{ Unadjusted } & \multicolumn{3}{|l|}{ Adjusted* } \\
\hline & Odds ratio & $(95 \% \mathrm{Cl})$ & $p$ & Odds ratio & $(95 \% \mathrm{Cl})$ & $p$ \\
\hline Warm $\left(\geq 18^{\circ} \mathrm{C}\right)$ & Ref. & & & Ref. & & \\
\hline Slightly cold $\left(12-18^{\circ} \mathrm{C}\right)$ & 1.83 & $(1.20,2.80)$ & 0.005 & 1.79 & $(1.14,2.81)$ & 0.011 \\
\hline Cold $\left(<12^{\circ} \mathrm{C}\right)$ & 2.14 & $(1.32,3.45)$ & 0.002 & 2.18 & $(1.27,3.75)$ & 0.005 \\
\hline
\end{tabular}

*Adjusted for region in Japan, age, sex, body mass index, household income, salt check sheet score, vegetable consumption, exercise, smoking, alcohol drinking, antihypertensive drug use, outdoor temperature in winter, and season of health checkup

other CV biomarkers. Shiue [39] analyzed the relationship between indoor temperature and CV biomarkers using data obtained from nurses' interviews of 7997 participants and showed that those living in houses with indoor temperatures below $18{ }^{\circ} \mathrm{C}$ had poor biomarker values. Saeki et al. [40] found a significant and independent association between low indoor temperatures and high platelet counts among 1095 elderly participants. However, these studies did not assess ECG, which reflects $\mathrm{CV}$ health and is recommended by WHO as an early detection and preventive method for CVD [19]. Thus, we expect our finding that low indoor temperatures are linked to ECG abnormalities will contribute to the progress of studies on housing and health.

A potential mechanism underlying the association between ECG abnormalities and low indoor temperatures is that daily cold stress stimulates sympathetic activity, which can lead to arrhythmias or cause coronary spasms to result in myocardial ischemia. Further, a large body of research has shown that hypertension causes ECG abnormalities such as left ventricular hypertrophy [41], myocardial infarction [42], arrhythmias [43], and atrioventricular block [44]. Based on evidence that low indoor temperatures increase BP [16-18], hypertension caused by living in cold houses may result in ECG abnormalities. Thus, rather than having only transient effects on blood pressure, living in cold houses may in fact have cumulative effects on ECG. These findings strengthen the significance of living in warm houses for the prevention of $\mathrm{CV}$ events.

In conjunction with lifestyle modifications, to reduce future CVD risk, we recommend improving the indoor home thermal environment. Previous systematic reviews have shown that interventions on lifestyle habits in longterm studies [45] or community studies [46] do not effectively reduce CVD risk. It may therefore be more effective to improve one's living environment simultaneously. There are 2 main strategies for improving the home thermal environment: live in a highly thermal insulated house and use heating devices. As shown in Fig. 3, while the heating pattern (the fluctuation in indoor temperature) and outdoor temperature were comparable between warm and slightly cold houses, the indoor temperature level was markedly different. This difference was driven in part by differences in thermal insulation levels. Furthermore, bedroom temperatures in the three groups 
were lower than living room temperatures throughout the day, which may be because partial heating of only the living room has become a habit in Japan. There is clearly room for improvement in the strategies used to increase the exposure temperature at home. Both strategies for improving the home thermal environment have strengths: living in a highly insulated house improves the thermal environment at an unconscious level, and using heating devices is a more practical choice in terms of time and cost. Thus, the combination of the two is recommended to improve the home thermal environment.

A major strength of the present study was that we used objective ECG data and 2-week indoor temperature measurements, which may have reduced biases due to the interposition of consciousness. Nevertheless, this study had several limitations. First, there is a selection bias because health checkup items were omitted at the doctors' discretion. So, valid samples might be biased toward participants at high risk of CVD. In fact, there are differences in basic characteristics between participants with ECG $(n=1480)$ and without ECG data $(n=676)$ (Table S2). Second, the time of the year during which participants conducted their health checkup varied from person to person. However, we inputted the season in which the health checkup was conducted (whether or not it was in winter) into the logistic model to adjust for seasonal variations in the CV biomarker. Third, we could not examine the association between indoor temperature and specific ECG abnormalities (e.g., arrhythmia, myocardial infarction, and atrial fibrillation) because of the small sample size. Finally, ECG monitoring was conducted for a relatively short time during the health checkup. In contrast to standard ECG, ambulatory ECG provides more information on an individual's heart health during daily life $[47,48]$. We, therefore, suggest that future research should include a subgroup in which ambulatory ECG monitoring is conducted and evaluate the relationship between ECG and indoor temperature based on longterm observations.

\section{Conclusions}

The present study showed a significant association between cold indoor temperatures and ECG abnormalities based on a cross-sectional study of 1480 participants in real-world settings. Our findings provide new insight in the field of housing and health. A clinical implication of our study is that keeping the indoor thermal environment within an appropriate range may contribute to good cardiovascular health. Besides lifestyle modifications, living in houses with high thermal insulation and appropriate use of heating devices can reduce CVD, and in turn EWM. Future long-term follow-up studies that compare residents in warm houses with those in cold houses should be conducted to confirm our findings.

\section{Abbreviations}

BMI: Body mass index; BP: Blood pressure; CV: Cardiovascular; CVD: Cardiovascular disease; ECG: Electrocardiogram; EWM: Excess winter mortality; JPY: Japanese Yen; SWH: Smart Wellness Housing; UK: United Kingdom; US CDC: United States Centers for Disease Control and Prevention; WHO: World Health Organization.

\section{Supplementary Information}

The online version contains supplementary material available at https://doi. org/10.1186/s12199-021-01024-1.

Additional file 1: Table S1. Details of abnormalities in electrocardiogram. Table S2. Basic characteristics of participants with and without ECG data. Table S3. Members of Smart Wellness Housing Survey Group. Figure S1. 47 prefectures in 8 regions in Japan. Figure S2. Definition of participants' exposure temperature. Figure $\mathbf{S 3}$. Distribution of average exposure time to living room and bedroom temperature.

\section{Acknowledgements}

We gratefully acknowledge the numerous construction companies, study investigators, and research committee members throughout all 47 prefectures in Japan who participated in the SWH survey. Members of the research committee for promotion of SWH who participated in this study are listed in Table S3.

\section{Authors' contributions}

Conceptualization, WU, TI, KK, YF, MS, SA, and SM; methodology, WU, TI, YF, MS, SA, and TH; validation, WU, TI, KK, YF, MS, and TH; formal analysis, WU; data curation, WU; writing —original draft preparation, WU; writing _-review and editing, TI, KK, YF, MS, SA, TH, TY, HY, and SM; visualization, WU; supervision, TI, KK, TY, HY, and SM; project administration, TI and SM; funding acquisition, $\mathrm{TI}$ and SM. All authors have read and agreed to the published version of the manuscript.

\section{Funding}

This study was partly supported by the Ministry of Land, Infrastructure, Transport, and Tourism as part of the Model Project for Promotion of SWH and a JSPS KAKENHI [Grant Numbers JP17H06151: Principal Investigator: Prof. Toshiharu Ikaga]. Funding organizations had no role in deciding the study design and conducting the study; collection, management, analysis, and interpretation of the data; preparation of the article; or the decision to submit the article for publication.

\section{Availability of data and materials}

The data presented in this study are available on request from the corresponding author. The data are not publicly available due to ethical restrictions.

\section{Declarations}

\section{Ethics approval and consent to participate}

The study was conducted according to the guidelines of the Declaration of Helsinki, and approved by the Ethics Committee of Hattori Clinic Ethics Review Board (approval number S1410-J03; date of approval: 14 Oct 2014). Informed consent was obtained from all subjects involved in the study.

\section{Consent for publication}

Not applicable.

\section{Competing interests}

TI has received research grants from Tokyo Gas Co., Ltd., Osaka Gas Co., Ltd., HyAS \& Co. Inc., Fuyo Home Co. Ltd., Asahi Kasei Homes Corp., OM Solar Co. Inc., Kajima Corp., Shimizu Corp., Nice Corp., Japan Gas Association, and Japan 
Sustainable Building Consortium. KK has received a research grant from Omron Healthcare Co., Ltd. YF has reported grants and personal fees from Saibugas Co., Ltd. MS has received non-restrictive research funds from Taiyo Nippon Sanso Corp. TH has received honorarium from LIXIL Corp. The above grants/funds/honorarium have been received outside the submitted work. The funders had no role in the design of the study; in the collection, analyses, or interpretation of data; in the writing of the manuscript; or in the decision to publish the results.

\section{Author details}

${ }^{1}$ Department of Architecture and Building Engineering, School of Environment and Society, Tokyo Institute of Technology, W8-11, 2-12-1, Ookayama, Meguro-ku, Tokyo 152-8552, Japan. ${ }^{2}$ Department of System Design Engineering, Faculty of Science and Technology, Keio University, Yokohama, Kanagawa, Japan. ${ }^{3}$ Department of Cardiology, Jichi Medical University School of Medicine, Shimotsuke, Tochigi, Japan. ${ }^{4}$ Department of Environmental Epidemiology, Institute of Industrial Ecological Sciences, University of Occupational and Environmental Health, Kitakyushu, Fukuoka, Japan. ${ }^{5}$ Department of Emergency Medicine, Ichikawa General Hospital, Tokyo Dental College, Ichikawa, Chiba, Japan. ${ }^{6}$ Department of Architecture, Faculty of Environmental Engineering, University of Kitakyushu, Kitakyushu, Fukuoka, Japan. ${ }^{7}$ Tokyo Metropolitan University, Hachioji, Tokyo, Japan. ${ }^{8}$ University of Occupational and Environmental Health, Kitakyushu, Fukuoka, Japan. ${ }^{9}$ Tohoku University, Sendai, Miyagi, Japan. ${ }^{10}$ Institute for Building Environment and Energy Conservation, Kojimachi, Chiyoda-ku, Tokyo, Japan.

\section{Received: 20 August 2021 Accepted: 27 September 2021} Published online: 12 October 2021

\section{References}

1. WHO. Integrated management of cardiovascular risk: Report of a WHO meeting, Geneva, 9-12 July 2002. 2002. https://www.who.int/cardiovasc ular_diseases/media/en/635.pdf. Accessed on 22 Jul 2021.

2. $\mathrm{WHO}$. Avoiding heart attacks and strokes: don't be a victim: protect yourself. 2005. http://apps.who.int/iris/bitstream/10665/43222/1/9241546727. pdf. Accessed on 22 Jul 2021.

3. WHO. Prevention of cardiovascular disease: Guideline for assessment and management of cardiovascular risk. 2007. http://apps.who.int/iris/bitst ream/handle/10665/43685/9789241547178_eng.pdf. Accessed on 22 Jul 2021

4. WHO, World Heart Federation, World Stroke Organization. Global atlas on cardiovascular disease prevention and control. 2011. http://apps.who.int/ iris/handle/10665/44701. Accessed on 22 Jul 2021.

5. WHO. Global action plan for the prevention and control of NCDs 2013-2020. 2013. http://apps.who.int/iris/bitstream/handle/10665/ 94384/9789241506236_eng.pdf. Accessed on 22 Jul 2021.

6. WHO. SHAKE the salt habit: Technical package for salt reduction. 2016. https://apps.who.int/iris/bitstream/handle/10665/250135/9789241511 346-eng.pdf. Accessed on 13 Sep 2021.

7. WHO. ACTIVE: a technical package for increasing physical activity. 2018 https://apps.who.int/iris/bitstream/handle/10665/275415/9789241514 804-eng.pdf? sequence=1\&isAllowed=y. Accessed on 13 Sep 2021.

8. WHO. MPOWER in action: defeating the global tobacco epidemic. 2013. https://apps.who.int/tobacco/mpower/publications/mpower_2013.pdf? ua=1. Accessed on 13 Sep 2021

9. The Eurowinter Group. Cold exposure and winter mortality from ischaemic heart disease, cerebrovascular disease, respiratory disease, and all causes in warm and cold regions of Europe. Lancet. 1997;349:1341-6. https://doi.org/10.1016/S0140-6736(96)12338-2.

10. Oberg AL, Ferguson JA, McIntyre LM, Horner RD. Incidence of stroke and season of the year: evidence of an association. Am J Epidemiol. 2000;152:558-64. https://doi.org/10.1093/aje/152.6.558.

11. Madaniyazi L, Chung Y, Kim Y, Tobias A, Ng CFS, Seposo X, et al. Seasonality of mortality under a changing climate: a time-series analysis of mortality in Japan between 1972 and 2015. Environ Health Prev Med. 2021;26:69. https://doi.org/10.1186/s12199-021-00992-8.

12. Davie GS, Baker MG, Hales S, Carlin JB. Trends and determinants of excess winter mortality in New Zealand: 1980 to 2000. BMC Public Health. 2007;7:263. https://doi.org/10.1186/1471-2458-7-263.
13. WHO Europe. Environmental burden of disease associated with inadequate housing. 2011. http://www.euro.who.int/_data/assets/pdf_file/ 0017/145511/e95004sum.pdf. Accessed on 22 Jul 2021.

14. Wilkinson P, Landon M, Armstrong B, Stevenson S, Pattenden S, McKee M, et al. Cold comfort: the social and environmental determinants of excess winter deaths in England, 1986-96. 2001. https://www.jrf.org.uk/report/ cold-comfort-social-and-environmental-determinants-excess-winterdeaths-england-1986-1996. Accessed on 22 Jul 2021.

15. WHO. WHO Housing and health guidelines. 2018. https://www.who.int/ publications/i/item/9789241550376. Accessed on 22 Jul 2021.

16. Saeki K, Obayashi K, Iwamoto J, Tone N, Okamoto N, Tomioka K, et al. Stronger association of indoor temperature than outdoor temperature with blood pressure in colder months. J Hypertens. 2014;32:1582-9. https://doi.org/10.1097/HJH.0000000000000232.

17. Wang Q, Li C, Guo Y, Barnett AG, Tong S, Phung D, et al. Environmental ambient temperature and blood pressure in adults: a systematic review and meta-analysis. Sci Total Environ. 2017;575:276-86. https://doi.org/10. 1016/j.scitotenv.2016.10.019.

18. Umishio W, Ikaga T, Kario K, Fujino Y, Hoshi T, Ando S, et al. Cross-sectional analysis of the relationship between home blood pressure and indoor temperature in winter: a nationwide smart wellness housing survey in Japan. Hypertension. 2019;74:756-66. https://doi.org/10.1161/HYPER TENSIONAHA.119.12914.

19. WHO. WHO list of priority medical devices for management of cardiovascular diseases and diabetes: WHO medical device technical series. 2021. https://www.who.int/publications/i/item/9789240027978. Accessed on 22 Jul 2021.

20. Rautaharju PM, Kooperberg C, Larson JC, LaCroix A. Electrocardiographic abnormalities that predict coronary heart disease events and mortality in postmenopausal women: The women's health initiative. Circulation. 2006:113:473-80. https://doi.org/10.1161/CIRCULATIONAHA.104.496091.

21. Auer R, Bauer DC, Marques-Vidal P, Butler J, Min LJ, Cornuz J, et al. Association of major and minor ECG abnormalities with coronary heart disease events. JAMA. 2012;307:1497-505. https://doi.org/10.1001/jama.2012. 434.

22. Ministry of Land, Infrastructure, Transport and Tourism. The present condition of existing housing stock (in Japanese). http://www.mlit.go.jp/ common/001105108.pdf. Accessed on 23 Jul 2021.

23. Umishio W, Ikaga T, Fujino Y, Ando S, Kubo T, Nakajima Y, et al. Disparities of indoor temperature in winter: a cross-sectional analysis of the nationwide smart wellness housing survey in Japan. Indoor Air. 2020;30:131728. https://doi.org/10.1111/ina.12708.

24. Yasutake K, Miyoshi E, Kajiyama T, Umeki Y, Misumi Y, Horita N, et al. Comparison of a salt check sheet with 24-h urinary salt excretion measurement in local residents. Hypertens Res. 2016;39:879-85. https://doi.org/ 10.1038/hr.2016.79.

25. Department of Health, UK. 2009 Annual Report of the Chief Medical Officer. 2010. http://www.sthc.co.uk/Documents/CMO_Report_2009.pdf. Accessed on 27 Jul 2021.

26. Brennan PJ, Greenberg G, Miall WE, Thompson SG. Seasonal variation in arterial blood pressure. BMJ. 1982;285:919-23. https://doi.org/10.1136/ bmj.285.6346.919.

27. Modesti PA, Morabito M, Bertolozzi I, Massetti L, Panci G, Lumachi C, et al. Weather-related changes in 24-hour blood pressure profile: effects of age and implications for hypertension management. Hypertension. 2006;47:155-61. https://doi.org/10.1161/01.HYP.0000199192.17126.d4.

28. Modesti PA, Morabito M, Massetti L, Rapi S, Orlandini S, Mancia G, et al. Seasonal blood pressure changes: an independent relationship with temperature and daylight hours. Hypertension. 2013;61:908-14. https:// doi.org/10.1161/HYPERTENSIONAHA.111.00315.

29. Stergiou GS, Palatini P, Modesti PA, Asayama K, Asmar R, Bilo G, et al. Seasonal variation in blood pressure: evidence, consensus and recommendations for clinical practice. Consensus statement by the European Society of Hypertension Working Group on Blood Pressure Monitoring and Cardiovascular Variability. J Hypertens. 2020;38:1235-43. https://doi. org/10.1097/HJH.0000000000002341.

30. Robinson D, Bevan EA, Hinohara S, Takahashi T. Seasonal variation in serum cholesterol levels - evidence from the UK and Japan. Atherosclerosis. 1992;95:15-24. https://doi.org/10.1016/0021-9150(92)90171-C.

31. Ockene IS, Chiriboga DE, Stanek EJ III, Harmatz MG, Nicolosi R, Saperia $\mathrm{G}$, et al. Seasonal variation in serum cholesterol levels: treatment 
implications and possible mechanisms. Arch Intern Med. 2004;164:86370. https://doi.org/10.1001/archinte.164.8.863.

32. Ma X, Yan H, Zhang H, Wang M, Zhang Q, Zhou X. Progress in the seasonal variations of blood lipids: a mini-review. Lipids Health Dis. 2020;19:108. https://doi.org/10.1186/s12944-020-01237-3.

33. Suarez $\mathrm{L}$, Barrett-Connor E. Seasonal variation in fasting plasma glucose levels in man. Diabetologia. 1982;22:250-3. https://doi.org/10.1007/ BF00281300.

34. Kershenbaum A, Kershenbaum A, Tarabeia J, Stein N, Lavi I, Rennert G. Unraveling seasonality in population averages: an examination of seasonal variation in glucose levels in diabetes patients using a large population-based data set. Chronobiol Int. 2011;28:352-60. https://doi. org/10.3109/07420528.2011.560315.

35. Halonen Jl, Zanobetti A, Sparrow D, Vokonas PS, Schwartz J. Outdoor temperature is associated with serum HDL and LDL. Environ Res. 2011;111:281-7. https://doi.org/10.1016/j.envres.2010.12.001.

36. Hong Y-C, Kim H, Oh S-Y, Lim Y-H, Kim S-Y, Yoon H-J, et al. Association of cold ambient temperature and cardiovascular markers. Sci Total Environ 2012;435-436:74-9. https://doi.org/10.1016/j.scitotenv.2012.02.070.

37. Basu R, (May) Wu X, Malig BJ, Broadwin R, Gold EB, Qi L, et al. Estimating the associations of apparent temperature and inflammatory, hemostatic, and lipid markers in a cohort of midlife women. Environ Res. 2017;152:322-7. https://doi.org/10.1016/j.envres.2016.10.023.

38. Sartini C, Barry SJE, Whincup PH, Wannamethee SG, Lowe GDO, Jefferis $\mathrm{BJ}$, et al. Relationship between outdoor temperature and cardiovascular disease risk factors in older people. Eur J Prev Cardiol. 2017;24:349-56. https://doi.org/10.1177/2047487316682119.

39. Shiue I. Cold homes are associated with poor biomarkers and less blood pressure check-up: English longitudinal study of ageing, 2012-2013. Environ Sci Pollut Res Int. 2016;23:7055-9. https://doi.org/10.1007/ s11356-016-6235-y.

40. Saeki K, Obayashi K, Kurumatani N. Platelet count and indoor cold exposure among elderly people: a cross-sectional analysis of the HEIJO-KYO study. J Epidemiol. 2017;27:562-7. https://doi.org/10.1016/j.je.2016.12. 018.

41. Kahan T, Bergfeldt L. Left ventricular hypertrophy in hypertension: its arrhythmogenic potential. Heart. 2005;91:250-6. https://doi.org/10.1136/ hrt.2004.042473.

42. Psaty BM, Furberg CD, Kuller LH, Cushman M, Savage PJ, Levine D, et al. Association between blood pressure level and the risk of myocardial infarction, stroke, and total mortality: The cardiovascular health study. Arch Intern Med. 2001;161:1183-92. https://doi.org/10.1001/archinte. 161.9.1183.

43. Lip GYH, Coca A, Kahan T, Boriani G, Manolis AS, Olsen MH, et al. Hypertension and cardiac arrhythmias: a consensus document from the European Heart Rhythm Association (EHRA) and ESC Council on Hypertension, endorsed by the Heart Rhythm Society (HRS), Asia-Pacific Heart Rhythm Society (APHRS) and Sociedad Latinoamericana de Estimulación Cardíaca y Electrofisiología (SOLEACE). Europace. 2017;19:891-911. https://doi.org/10.1093/europace/eux091.

44. Kerola T, Eranti A, Aro AL, Haukilahti MA, Holkeri A, Junttila MJ, et al. Risk factors associated with atrioventricular block. JAMA Netw Open. 2019;2. https://doi.org/10.1001/jamanetworkopen.2019.4176.

45. Hooper L, Bartlett C, Smith GD, Ebrahim S. Systematic review of long term effects of advice to reduce dietary salt in adults. BMJ. 2002;325:628-32. https://doi.org/10.1136/bmj.325.7365.628.

46. Pennant M, Davenport C, Bayliss S, Greenheld W, Marshall T, Hyde C. Community programs for the prevention of cardiovascular disease: a systematic review. Am J Epidemiol. 2010;172:501-16. https://doi.org/10. 1093/aje/kwq171.

47. Crawford MH, Bernstein SJ, Deedwania PC, JP DM, Ferrick KJ, Garson AJ, et al. ACC/AHA guidelines for ambulatory electrocardiography: Executive summary and recommendations: a report of the American college of Cardiology/American heart association task force on practice guidelines (committee to revise the guidelines for ambulatory electrocardiography): Developed in collaboration with the north American society for pacing and electrophysiology. Circulation. 1999;100:886-93. https://doi.org/10. 1161/01.CIR.100.8.886.

48. Steinberg JS, Varma N, Cygankiewicz I, Aziz P, Balsam P, Baranchuk A, et al. 2017 ISHNE-HRS expert consensus statement on ambulatory ECG and external cardiac monitoring/telemetry. Heart Rhythm. 2017;14:e55-96. https://doi.org/10.1016/j.hrthm.2017.03.038.

\section{Publisher's Note}

Springer Nature remains neutral with regard to jurisdictional claims in published maps and institutional affiliations.
Ready to submit your research? Choose BMC and benefit from:

- fast, convenient online submission

- thorough peer review by experienced researchers in your field

- rapid publication on acceptance

- support for research data, including large and complex data types

- gold Open Access which fosters wider collaboration and increased citations

- maximum visibility for your research: over $100 \mathrm{M}$ website views per year

At BMC, research is always in progress.

Learn more biomedcentral.com/submissions 